Ambiente \& Água - An Interdisciplinary Journal of Applied Science
ISSN 1980-993X - doi:10.4136/1980-993X
www.ambi-agua.net
E-mail: ambi-agua@agro.unitau.br

\title{
Avaliação físico-química e microbiológica do soro de leite concentrado obtido por osmose inversa
}

\author{
doi: 10.4136/ambi-agua.1316
}

Received: 12 Feb. 2014; Accepted: 21 May 2014

\author{
Ana Cláudia Desconsi ${ }^{1}$; Hélcio José Izário Filho² \\ Rodrigo Fernando dos Santos Salazar ${ }^{3 *}$

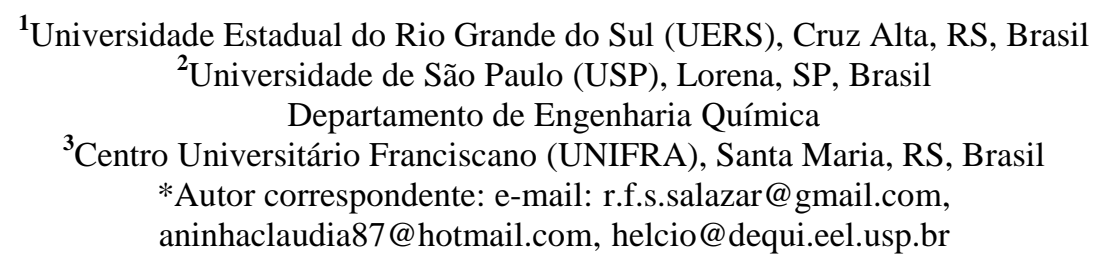

\section{RESUMO}

O processamento de leite para produção de queijo gera uma grande quantidade de soro. Este subproduto de laticínios pode ser considerado como matéria-prima na indústria de alimentos, especialmente em produtos agroindustrial para complementar e suplementar alimentos. Neste sentido, o objetivo deste trabalho foi avaliar a estabilidade e caracterizar físico-químico e microbiologicamente o soro de leite concentrado obtido por osmose inversa a partir de resíduos do processamento de mussarela. Foram analisadas amostras de soro de leite resultantes de diferentes estágios de processamento, tais como: soro de leite pasteurizado, soro de leite de silos de armazenagem, soro de leite concentrado e permeado. As determinações analíticas realizadas foram temperatura, acidez titulável $\left({ }^{\circ} \mathrm{D}\right),{ }^{\circ} \mathrm{BRIX}$, densidade, extrato seco total, gordura total, $\mathrm{pH}$, coliforme total, coliforme termotolerantes e micro-organismos aeróbios mesófilos empregando procedimentos do Standard Methods for the Examination of Dairy Products. Micro-organismos mesófilos foram observados em todas as amostras. Apesar deste indicativo, a contagem de bactérias aeróbias mesófilas presentes no soro tratado por osmose inversa apresentou uma contagem abaixo da referência $\left(1 \times 10^{5} \mathrm{UFC}\right.$ $\mathrm{mL}^{-1}$ ). O soro de leite concentrado apresentou temperatura de $8^{\circ} \mathrm{C}$, acidez titulável de $22^{\circ} \mathrm{D}$, sólidos igual a $18^{\circ} \mathrm{BRIX}$, densidade de $1085 \mathrm{~g} \mathrm{~cm}^{-3}$, percentual de extrato seco total em torno de $30,0 \%$ e pH de 6,4. O soro concentrado apresentou teor de gordura percentual menor que $4 \%$. Observou-se que o soro de leite concentrado é um produto com elevado valor nutricional e estabilidade microbiológica quando imediatamente submetido à osmose inversa. Por conseguinte, as concentrações de soro de leite avaliadas nesta investigação atendem aos requisitos técnicos e sanitários para consumo humano.

Palavras-chave: OI, queijo mussarela, análise microbiológica. 


\title{
Physicochemical and microbiological evaluation of concentrated whey obtained by reverse osmosis
}

\begin{abstract}
The processing of milk during cheese making generates a large amount of whey. This by-product can be considered raw material in the food industry and especially in agro-industrial products where it may be used to complement and supplement food. In this context, we evaluated the stability and physicochemical and microbiological aspects of concentrated whey obtained by reverse osmosis of dairy waste from mozzarella processing. We collected whey samples from different stages of processing, such as pasteurized whey, silo-stored whey, concentrated whey and water-permeated whey. The Standard Methods for the Examination of Dairy Products was employed and the following parameters were analyzed: temperature, titratable acidity $\left({ }^{\circ} \mathrm{D}\right),{ }^{\circ} \mathrm{BRIX}$, density, total dry extract, total fat, $\mathrm{pH}$, total coliform, thermotolerant coliform and mesophilic aerobic microorganisms. Mesophilic microorganisms were observed in all samples. However, the mesophilic count in treated whey by reverse osmosis was below the reference value $\left(1 \times 10^{5} \mathrm{CFU} \mathrm{mL} \mathrm{m}^{-1}\right)$. The concentrated whey had a temperature of above $8{ }^{\circ} \mathrm{C}$, titratable acidity of $22^{\circ} \mathrm{D}$, around $18{ }^{\circ} \mathrm{BRIX}$ of soluble solids, density equals to $1085 \mathrm{~g} \mathrm{~cm}^{-3}$, percentage of total solids of $30.0 \%$ and $\mathrm{pH}$ of 6.4 . The concentrated whey had less than $4 \%$ fat. It could be observed that the concentrated whey is a product with high nutritional value and microbiological stability when immediately subjected to reverse osmosis. Consequently, the concentrated whey obtained and evaluated in this investigation presents technical and sanitary characteristics for human consumption.
\end{abstract}

Keywords: whey, RO, mozzarella cheese, microbiological analysis.

\section{INTRODUÇÃO}

O soro de leite é o líquido resultante da coagulação do leite na produção de queijo e contém cerca de metade dos componentes sólidos presentes no leite (lactose, lipídios, minerais, proteínas e vitaminas). Portanto, o soro pode ser considerado um subproduto da indústria de laticínios de grande importância devido ao volume produzido e seu alto valor nutritivo (Miller et al., 2000; Oliveira et al., 2012). Durante muitos anos o soro foi considerado um resíduo industrial e, por conseguinte, grandes quantidades deste subproduto foram descartadas pré-tratadas ou diretamente em rios ou como um suplemento para ração animal (Fox e McSweeney, 1998; Loures et al., 2013; Salazar et al., 2013). Com base nos problemas enfrentados pelas empresas de laticínios para atender as exigências dos órgãos de fiscalização de saúde e ambiental em diferentes esferas de governo e, paralelamente, maior rigor e sensibilização da sociedade sobre os danos que esta atividade pode causar ao meio ambiente, muitos trabalhos vem sendo propostos que vão desde: 1) o uso de soro de leite como suplemento alimentar; 2) tecnologias que facilitem o reaproveitamento parcial ou integral dos componentes presentes no soro (Moreira et al., 2010; Oliveira et al., 2012; Florêncio et al., 2013); 3) bem como para o tratamento adequado e eliminação da parte restante do material que não é reciclado ou reprocessado (Fox e McSweeney, 1998; Souza et al., 2010; Aydiner et al., 2013; Loures et al., 2013; Salazar et al., 2013).

No Brasil, o soro de leite vem sendo utilizado principalmente na indústria de alimentos na produção de ricota, queijo tipo cottage, além de utilizado como ingrediente em alguns produtos lácteos fermentados (Mizubuti, 1994; Oliveira et al., 2012). Conforme Morr e Ha (1993) existem dois tipos de soro de queijo, o soro ácido e o soro doce. O soro ácido apresenta $\mathrm{pH}$ de 4,6 sendo resultante de manufatura de caseína ou de queijos feitos com leite 
coagulados inicialmente por ácido, tal como o queijo cottage, quark, requeijão e ricota. O soro doce é proveniente da coagulação enzimática do leite e apresenta $\mathrm{pH}$ em torno de 6,3 e 6,7 sendo obtido de queijos tipo cheddar, minas frescal, minas padrão e mussarela (Morr e Ha, 1993). Paralelamente, outros setores tecnológicos vêm demonstrando a potencialidade do emprego do soro lácteo (Revillion et al., 2000; Oliveira et al., 2012; Florêncio et al., 2013). Florêncio et al. (2013) avaliaram a possibilidade de emprego do soro para a produção de etanol de segunda geração apontando o potencial desse material para o emprego no setor energético, demonstrando que há muitas aplicações para o soro do leite.

As operações de separação por membranas são utilizadas para se concentrar e fracionar o fluido obtendo-se duas soluções com composições diferentes. Entre os sistemas de filtração, aqueles que fazem uso de membranas de ultrafiltração (UF), nanofiltração (NF) e osmose inversa (OI) têm sido amplamente utilizados para a reciclagem de componentes do soro do leite pelas indústrias leiteiras (Balannec et al., 2002; Akoum et al., 2004, Ordoñez, 2005). Segundo Ordóñez (2005) a osmose inversa retém moléculas com tamanho inferior a $1 \mathrm{~nm}$ necessitando de condições de pressões elevada para superar o aumento da pressão osmótica do concentrado. As moléculas de água passam uma solução concentrada (corrente de alimentação) para uma solução diluída (permeado). Ela é utilizada para concentrar o leite, soro e nata, bem como desmineralização e recuperação de lactose a partir de soro de leite (Gillies, 1974; Ordóñez, 2005). Os sistemas de osmose inversa são caracterizados pelo uso de membranas semipermeáveis com diâmetro menor que $0,001 \mu \mathrm{m}$ e capacidade de operar com pressões compreendidas entre $1500 \mathrm{kPa}$ a $15000 \mathrm{kPa}$ e são os que mais têm sido investigados para diversas aplicações nas empresas de laticínios (Balannec et al., 2002; Akoum et al., 2004; Tawfik et al., 2006; Vourch et al., 2008; Souza et al., 2010; Aydiner et al., 2013).

Balannec et al. (2002) avaliaram o desempenho de membranas de ultrafiltração, nanofiltração e osmose inversa para tratar água oriunda de efluente lácteo e demonstraram a eficácia de um sistema que contém uma membrana de ultrafiltração para a retenção de sólidos provenientes do leite. No entanto, o sistema proposto não foi eficiente para garantir um padrão aceitável para a reutilização dessa água de lavagem. Por outro lado, Vourch et al. (2008) apresentaram uma recuperação de 95\% de água reciclada, trabalhando com um caudal de $100 \mathrm{~m}^{3} \mathrm{dia}^{-1}$ para tratar as águas de lavagem das indústrias leiteiras francesas que empregavam membranas de osmose inversa. De qualquer forma, os autores não comentam sobre a reutilização ou eliminação da torta de sólidos gerada por dia de produção (Tawfik et al., 2006; Vourch et al., 2008). Dependendo das características finais destes resíduos o soro retido nas membranas pode não ter os requisitos necessários para servir como um componente na produção de outros alimentos e, além disso, acarretar em passivos ambientais e sanitários. Em contrapartida, desde meados de 1990, os sistemas de separação moleculares vêm sendo amplamente adotados no Brasil para diversos empregos na indústria de alimentos, principalmente, para concentrar vários líquidos como sucos de frutas, sucos vegetais e leite (Mizubuti, 1994). Consequentemente o soro de leite processado vem sendo empregado em diferentes formulações de alimentos infantis e farmacêuticos, suplementos vitamínicos e bebidas lácteas, demonstrando haver a necessidade de mais investimento e conhecimento sobre o potencial econômico e nutricional do soro de leite (Mizubuti, 1994; Revillion et al., 2000; Moreira et al., 2010; Oliveira et al., 2012).

Neste sentido, buscou-se avaliar físico-químico e microbiologicamente o soro de leite concentrado obtido por osmose inversa, verificando se o mesmo possui qualidade para ser empregado como matéria-prima de outros segmentos da indústria de alimentos. 


\section{MATERIAL E MÉTODOS}

\subsection{Amostra}

O soro utilizado nestes estudos foi adquirido de um laticínio de grande porte que produz derivados lácteos líquidos, tendo como principal produto o queijo mussarela. Essa empresa é localizada na Região Oeste do Estado de Santa Catarina, Brasil. Este soro é obtido por coagulação do leite na produção de queijo mussarela e foi obtido a partir de duas bateladas dessa produção ao longo do $1^{\circ}$ semestre de 2012, totalizando uma amostragem com 24 tubos estéreis por batelada. Este material consistia de soro de leite doce e era caracterizada por ser um líquido turvo com coloração amarelo-esverdeada. A amostragem consistiu de 6 tubos com soro de leite pasteurizado, 6 tubos com soro de leite concentrado e 6 tubos contendo permeado resultante do processo de osmose inversa. As amostras foram colhidas assepticamente em tubos estéreis com rosca. Os frascos foram identificados e armazenados em câmara fria a $4{ }^{\circ} \mathrm{C}$ até à análise. As análises foram realizadas nos laboratórios da empresa de laticínios. Os procedimentos analíticos para determinações físico-químicas e microbiológicas foram extraídos de métodos padrão para o exame dos produtos lácteos e realizados em quadruplicata (APHA et al., 2004).

\subsection{Análise microbiológica}

A avaliação microbiológica consistiu em determinar a carga microbiana presente nas amostras provenientes de diferentes etapas do processo por osmose inversa. A contagem de coliformes termotolerantes, bactérias aeróbias mesófilas e coliformes totais foram realizados em amostras de soro de leite líquido pasteurizado, soro de leite em um recipiente de armazenamento, soro de leite concentrado e permeado de água. Os procedimentos e a rotina analítica adotada para os ensaios microbiológicos seguiram as normativas contidas no Standard Methods for the Examination of Dairy Products propostos por APHA et al. (2004). Foram empregados o meio molten PCA (Plate Count Agar, mantido a 42-45 ${ }^{\circ} \mathrm{C}$ ) utilizado em bacteriologia alimentar para quantificar bactérias aeróbias no leite; meio EC (MacConkey Agar Base, HIMEDIA) para contagem seletiva de coliformes termotolerantes e coliformes totais; membranas e meios de cultura 3MT-Petrifilm para a análise microbiológica da água resultante do processo de osmose inversa.

\subsection{Caracterização físico-química}

A caracterização físico-química consistiu em determinar a temperatura $\left({ }^{\circ} \mathrm{C}\right)$, a acidez titulável $\left({ }^{\circ} \mathrm{D}\right)$, açúcares totais $\left({ }^{\circ} \mathrm{BRIX}\right)$, densidade $\left(\mathrm{g} \mathrm{cm}^{-3}\right)$, extrato seco total $(\mathrm{g})$, gordura $(\mathrm{g})$ e o pH em amostras de soro de leite líquido e soro de leite pasteurizado concentrado, conforme metodologia estabelecida por Zenebon et al. (2008). As soluções foram preparadas utilizando reagentes de grau analítico, água ultra pura obtida usando sistema de água Milli-Q (Millipore Corp, de Billerica, MA, EUA) a resistividade de 18,2 $\mathrm{M} \Omega \mathrm{cm}$, ácido nítrico e clorídrico (Merck, Darmstadt, Alemanha) destiladas em quartzo sub-ebulição (Milestone, Sorisole, Itália). Para evitar a contaminação, os frascos, vidrarias e materiais de polipropileno foram lavadas e embebidas em $10 \% \mathrm{v} \mathrm{v}^{-1} \mathrm{HNO}_{3}$ e completamente lavados com água deionizada. Solução Dornic $(\mathrm{NaOH} N / 9)$, fenolftaleína $\left(1 \% \mathrm{v} \mathrm{v}^{-1}\right)$, ácido sulfúrico $(\mathrm{D}=1,825)$ e álcool isoamilico $(\mathrm{D}=0,815)$ foram utilizadas para caracterizações físico-químicas.

\subsection{Processamento do soro por sistema por OI}

O diagrama de fluxo para a produção de soro de leite concentrado por osmose inversa é demonstrado a seguir (Figura 1): 


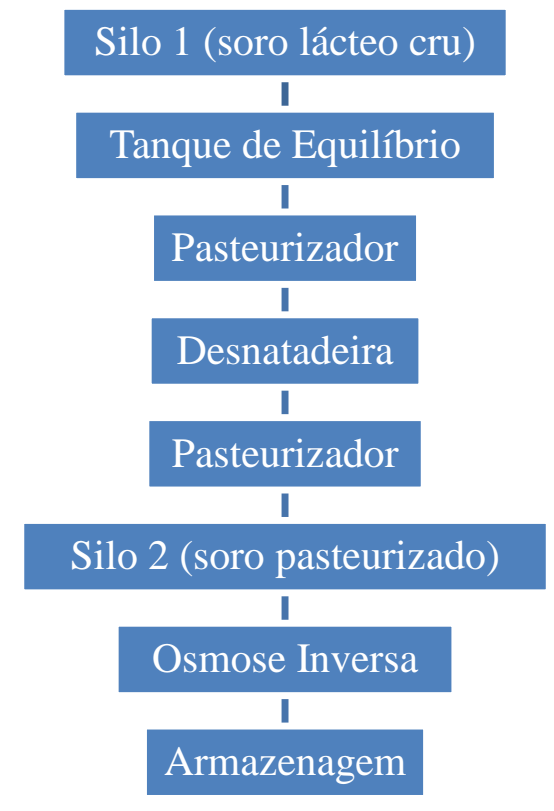

Figura 1. Fluxograma da produção de soro de leite concentrado a partir do soro de leite obtido do processamento de queijo mussarela.

A partir da Figura 1 é possível identificar as etapas que a amostragem foi realizada. As amostras de soro de leite eram retiradas do Silo 1 enquanto que as amostras de soro de leite pasteurizado foram retiradas após a pasteurização. Alíquotas de soro de leite concentrado foram retirados do Silo 2 enquanto que as amostras de permeado resultante do processo de osmose inversa eram coletadas após todo o processamento do soro de leite.

O soro de leite proveniente do processamento do queijo era bombeado para dentro do silo 1 (soro de leite cru). Este silo tinha capacidade para $100 \mathrm{~m}^{3}$ e estava localizado na parte externa do Setor de Osmose Inversa. Em seguida, o soro de leite era enviado para o tanque de equilíbrio localizado dentro do mesmo setor. Logo depois o soro de leite era submetido à pasteurização HTST (High Temperature and Short Time). O sistema de pasteurização era composto por trocadores de calor de placas e o binômio temperatura/tempo empregado foi de $74{ }^{\circ} \mathrm{C} / 15 \mathrm{~s}$ até $20 \mathrm{~s}$, respectivamente. Após a pasteurização, o soro foi submetido à desnatadeira para remover óleos e gorduras presentes para atender aos padrões legais que exigem que esse compostos represente de 0,0 e 0,6\% do total dos componentes sólidos no mesmo. Simultaneamente, o creme resultante da desnatadeira foi enviado à fabricação de manteiga. Por fim, o soro de leite foi submetido a pasteurizador e arrefecido para $7,0{ }^{\circ} \mathrm{C}$ e armazenado no silo 2 (soro pasteurizado).

O soro de leite pasteurizado era submetido ao processo de filtração por osmose inversa. A temperatura de entrada foi controlado em $8{ }^{\circ} \mathrm{C}$. A concentração ocorria em $20 \mathrm{~min}$, sendo finalizado quando o soro de leite concentrado apresentasse $15^{\circ}$ BRIX. Os padrões de referência utilizados para o processamento de leite e soro de leite seguiu as normas estabelecidas pelo Ministério da Agricultura, Pecuária e Abastecimento, o Brasil (IN nº. 62/2011) (Brasil, 2011).

\section{RESULTADOS E DISCUSSÃO}

\subsection{Análise microbiológica}

Os resultados da caracterização microbiológica são mostrados na Tabela 1 para a primeira e segunda batelada de processamento de queijo mussarela. 
Tabela 1. Média dos valores referente à análise microbiológica em diferentes pontos de processamento para as bateladas 1 e 2 para a produção de soro de leite concentrado. $(n=4)$.

\begin{tabular}{ccccccc}
\hline & $\begin{array}{c}\text { Coliforme Total } \\
\left.(\mathrm{UFC} \mathrm{mL})^{-1}\right)\end{array}$ & \multicolumn{2}{c}{$\begin{array}{c}\text { Coliforme } \\
\text { Termotolerante } \\
\left(\mathrm{UFC} \mathrm{mL}^{-1}\right)\end{array}$} & $\begin{array}{c}\text { Bactérias aeróbias } \\
\text { mesófilas } \\
\left(\mathrm{UFC} \mathrm{mL}^{-1}\right)\end{array}$ \\
\hline Batelada & $1^{\mathrm{a}}$ & $2^{\mathrm{a}}$ & $1^{\mathrm{a}}$ & $2^{\mathrm{a}}$ & $1^{\mathrm{a}}$ & $2^{\mathrm{a}}$ \\
\hline Soro previamente estocado & 4 & 0 & 4 & - & $>3000$ & $>3000$ \\
Soro pasteurizado & 2 & 0 & 2 & - & 248 & 540 \\
Água de osmose & 0 & 21 & - & 14 & 11 & 37 \\
Soro concentrado & 4 & 1 & - & 0 & 250 & 380 \\
\hline
\end{tabular}

Conforme o Projeto de Instrução Normativa que estabelece os padrões de identidade e qualidade de soro de leite (2013) os produtos "Soro de leite" e "Soro de leite Concentrado" devem cumprir com os seguintes critérios de qualidade microbiológicos: i) contagem de aeróbios mesófilos viáveis até $1,5 \times 10^{5}$; ii) contagem de coliformes totais até $1,0 \times 10^{3}$ e iii) contagem de termotolerantes até $1,0 \times 10^{2}$.

Com base nestes resultados verificou-se que as amostras de soro de leite pasteurizado previamente armazenadas mostraram que o soro estocado, devido à presença de bactérias aeróbicas mesófilas, apresentou baixa estabilidade microbiológica. Entretanto verifica-se que o soro não apresentou coliformes totais e termotolerantes em concentrações que condenasse o soro oriundo dessas duas bateladas. As amostras de água de osmose não apresentaram teores de coliformes termotolerantes. A amostra de soro de leite concentrada apresentou baixa concentração de coliformes totais $\left(4 \mathrm{UFC} \mathrm{mL}^{-1}\right)$, ausência de coliforme termotolerante e apresentou micro-organismos mesófilos.

Ao analisar a segunda batelada observou-se elevada concentração de mesófilos em amostras de soro de leite pasteurizado, bem como de soro de leite previamente armazenado. Por outro lado, não houve contaminação por coliformes. Nas amostras de soro de leite concentrados não houve contaminação por coliformes totais e termotolerantes. $\mathrm{Na}$ amostra de água de osmose (permeado de água através do processo de osmose inversa), os coliformes totais formados ficaram em torno de $21 \mathrm{UFC} \mathrm{mL}^{-1}$. Desse total, $14 \mathrm{UFC} \mathrm{mL}^{-1}$ representam coliformes termotolerantes. Em relação ao soro concentrado houve a formação de uma única colônia de coliforme total e ausência de coliforme termotolerante. A partir da análise das duas bateladas observa-se a capacidade do sistema de pasteurização e osmose inversa em minimizar a presença de mesófilos e coliformes no soro concentrado. Deste modo pode-se dizer que o sistema de osmose inversa eleva o tempo de conservação do soro quando concentrado e atendia aos padrões de qualidade do soro de leite (Brasil, 2013).

A presença de micro-organismos mesófilos encontrados no soro previamente armazenado pode indicar que o produto estava contaminado devido a muitos fatores, entre eles à falta de higiene durante a etapa de estocagem, contaminação durante o processamento, limpeza insuficiente dos equipamentos ou as condições impróprias de tempo e temperatura durante a pasteurização e armazenamento (Gillies, 1974; Spangler e Amundson, 1986; Ordoñez, 2005; Souza et al., 2010). No entanto, a presença de micro-organismos aeróbios mesófilos foi identificada apenas em silos de pré-concentrado de soro de leite. Deste modo é possível que a presença de micro-organismos é mais condicionado à natureza perecível deste material do que dificuldades no controle higiênico-sanitário (Gillies, 1974; Miller et al., 2000; APHA et al., 2004). Deste modo, deve-se ter maior controle sobre a otimização do tempo de armazenamento ou do procedimento utilizado para o armazenamento, a fim de minimizar a proliferação de micro-organismos aeróbios mesófilos. Outra possibilidade seria o 
processamento imediato de pré-concentrados soro líquido. No entanto, o processamento de soro de leite é condicionado diretamente à procura.

De qualquer forma os valores obtidos estão dentro do permitido e prescritos pela empresa e regulamentados pelo Ministério da Agricultura, Pecuária e Abastecimento (Brasil, 2013).

Em ambos os casos houve a eficiência de filtração de osmose inversa para a pré-concentração de soro de leite e para a redução da carga microbiana ou microbiota, em especial. Possivelmente, a redução da carga microbiana ocorre devido ao aumento da concentração de caseína e outros componentes sólidos presentes no soro do leite, a tornandose um meio hipertônico (Morr e Ha, 1993; Fox e McSweeny, 1998).

\subsection{Caracterização físico-química}

O resultado das análises físico-químicas de amostras de soro de leite líquido e do soro de leite concentrado obtido por osmose inversa é mostrado na Tabela 2.

Tabela 2. Média dos valores referentes aos parâmetros físico-químicas avaliadas em soro líquido e soro concentrado. $(n=4)$.

\begin{tabular}{lcccc}
\hline \multirow{2}{*}{ Parâmetros } & \multicolumn{4}{c}{ Amostragem de soro } \\
\cline { 2 - 5 } & Líquido & Padrão $^{\mathbf{1}}$ & Concentrado & Padrão $^{\mathbf{1}}$ \\
\hline Temperatura $\left({ }^{\circ} \mathrm{C}\right)$ & $10 \pm 3$ & $<15$ & $8 \pm 1$ & $<10$ \\
Acidez titulável (Dornic $\left.-{ }^{\circ} \mathrm{D}\right)$ & $15 \pm 1$ & 16 & $22 \pm 2$ & $18,0 \_28,0$ \\
Gordura $(\%)$ & 0,0 & $<0,4$ & 0,0 & $<0,4$ \\
Densidade $\left(\mathrm{g} \mathrm{cm}^{-3}\right)$ & $1026 \pm 3$ & $1020_{-} 1030$ & $1085 \pm 6$ & $1060 \_1100$ \\
Extrato sólido total $(\%)$ & $6,0 \pm 0,4$ & $5,25 \_7,75$ & $30,0 \pm 0,5$ & $>16,5 \%$ \\
pH & $6,50 \pm 0,2$ & $6,00_{-} 6,70$ & $6,4 \pm 0,3$ & $6,22_{-} 6,8$ \\
${ }^{\circ}$ BRIX & -- & -- & $18 \pm 1$ & $17_{-} 20$ \\
\hline
\end{tabular}

Nota: ${ }^{1}$ Os padrões de referência foram estabelecidos de acordo com as exigências industriais para o processamento de soro de leite em grande escala e pela legislação brasileira para qualidade do leite (Brasil, 2011).

Com base nos dados obtidos, verifica-se que o soro de leite líquido proveniente do pasteurizador era adequado para o processamento e concentração por osmose inversa sem que houvesse grandes perdas de as suas características físico-químicas. O Projeto de Instrução Normativa para os padrões de identidade e qualidade de soro de leite (2013) estabelece, como requisitos físico-químicos para o soro de leite e soro concentrado a serem submetidos à alimentação humana, os seguintes requisitos: i) pH entre 6,0 e 6,8; ii) acidez titulável (g / 100 g) entre 0,08 e 0,14; e iii) o mínimo de 5,0 g de sólidos totais (g / $100 \mathrm{~mL}$ ) para soro de leite. Em relação ao soro de leite concentrado, o Projeto de Instrução Normativa (2013) estabelece que esse produto deve apresentar concentração de sólidos totais superior a $11,0 \mathrm{~g} / 100 \mathrm{~mL}$ e que o mesmo seja negativo para reconstituintes de densidade e neutralizantes de acidez. Ao comparar os resultados físico-químicos obtidos com os requisitos necessários prescritos verificou-se que o soro de leite concentrado enquadrou-se aos critérios estabelecidos no Projeto de Instrução Normativa (Brasil, 2013).

Conforme Morr e Ha (1993) o teor de extrato seco total (EST), no processo de concentração do soro de leite, pode representar um parâmetro semi-quantitativo sobre a quantidade de proteínas no soro. Quanto maior a concentração do teor total de proteína, maior o valor agregado (Oliveira et al., 2012). Neste contexto, pode-se dizer que sistema OI apresentado nesse trabalho apresentou elevada eficiência para obtenção de EST em torno de 30\%, pois, conforme Mizubuti (1994), o sistema OI quando operando em condições padrão, 
deixa o soro com um teor de EST ao redor de $20 \%$. Considerando que o teor de extrato seco total é da ordem de 5,0 \% (Morr e Ha, 1993; Oliveira et al., 2012) foi possível trabalhar com fator de concentração de ordem 6 , superior ao fator de concentração reportado na revisão feita por Mizubuti (1994).

Por conseguinte, a concentração de soro de leite obtido neste laticínio apresentou as características para consumo humano e dentro dos parâmetros estabelecidos no Projeto de Instrução Normativa que estabelece os padrões de identidade e qualidade de soro de leite (Brasil, 2013). Consequentemente, o soro de leite concentrado obtido pode ser comercializado como um suplemento alimentar ou como matéria-prima para outras empresas de gêneros alimentícios. Quando o soro obtido por osmose inversa não apresentasse as características necessárias para o consumo humano, este material era destinado para fábricas de ração animal como um suplemento para a elaboração de ração animal.

\subsection{Características gerais do processo de $\mathrm{OI}$}

Em geral, o processamento do soro de leite por osmose inversa utilizada neste estudo foi caracterizado pela entrada de soro com caudal de $319 \mathrm{~m}^{3} \mathrm{~h}^{-1}$ por meio de um filtro operando com pressão de 9,5 bar e $8{ }^{\circ} \mathrm{C}$. O processo de filtração por osmose inversa foi otimizado para operar com capacidade para filtrar $20 \mathrm{~m}^{3}$ de soro por hora, resultando em $15 \mathrm{~m}^{3}$ de água permeada e $5 \mathrm{~m}^{3}$ de soro de leite concentrada. Nessa condição de operação e durante a realização desse estudo verificou-se que as membranas apresentaram tempo de vida útil elevado, necessitando da manutenção de rotina e limpeza a cada batelada com extrato enzimático e parada no sistema para desentupimento a cada 30-35 dias. Diversos estudos na literatura sobre o emprego de membranas de OI indicam que o fluxo de permeado é o parâmetro que mais influencia na eficiência de concentração e no tempo de vida útil dos materiais que perfazem as membranas OI, concluindo que esse fator governa em grande escala a viabilidade econômica desse tipo de processo (Skudder et al., 1977; Toledo, 1984; Spangler e Amundson, 1986; Mizubuti, 1994).

Spangler e Amundson (1986) e Mizubuti (1994) comentam que, para otimizar o emprego dessas membranas para a concentração de soro lácteo, deve-se levar em consideração os fatores que afetam a velocidade de fluxo do permeado tais como: propriedades das membranas (Ex.: blenda de acetato de celulose - CA, ou compósito de filme fino - TFC), a composição do alimento e as condições do processo. Nesse sentido verificou-se que, em condições de caudal, pressão e temperatura otimizados, o soro de leite na entrada apresentou $7^{\circ} \mathrm{BRIX}, \mathrm{pH} 6,27$ e acidez de $12,3^{\circ} \mathrm{D}$. O soro de leite concentrado foi obtido com $18^{\circ} \mathrm{BRIX}$, $\mathrm{pH} 6,19$, a uma temperatura de $10^{\circ} \mathrm{C}$. A água resultante do processo de filtração era enviada para contêineres com $20 \mathrm{~m}^{3}$ e utilizada para a limpeza. O efluente gerado o qual não pode ser reutilizado eram destinados para sistema de tratamento biológico de efluentes. O soro de leite concentrada podia ser submetido a duas rotas. Uma parte era bombeada para um tanque de estocagem localizado na parte externa do setor de processamento por osmose inversa e a outra parte era submetida à secagem por spray drying para a obtenção de soro em pó.

$\mathrm{O}$ uso desta tecnologia de filtração teve como principal vantagem a obtenção de soro de leite que pode ser usado como suplemento alimentar ou como matéria-prima para as empresas de alimentos, como as empresas de panificação, produtos de carne, sorvetes, bebidas lácteas e ração animal (Miller et al., 2000; Balannec et al., 2002; Ordoñez, 2005; Souza et al., 2010).

\section{CONCLUSÕES}

O sistema de filtração por osmose inversa apresentou uma série de vantagens, tais como: i) baixo custo energético para manter a temperatura durante o processamento de cerca de $5 \mathrm{e}$ $10^{\circ} \mathrm{C}$; ii) manutenção das características físico-químicas avaliadas durante a concentração, 
mantendo a qualidade do soro de leite processado; iii) houve agregação de valor para o soro de leite devido a remoção de água e pelo aumento do teor de extrato seco total; iv) eficiência na redução dos coliformes totais e bactérias aeróbias mesófilas bem como a ausência de bactérias termotolerantes e; v) por fim, devido a concentração do soro de leite por meio deste sistema verificou-se o aumento do tempo de prateleira porque, através da redução da quantidade de água, houve uma redução da atividade de água $\left(\mathrm{A}_{\mathrm{w}}\right)$, tornando-o mais estável microbiologicamente.

Em relação ao processo de OI verificou-se que o fluxo de permeado otimizado (com caudal de $319 \mathrm{~m}^{3} \mathrm{~h}^{-1}$, pressão 9,5 bar e $8^{\circ} \mathrm{C}$ ) foi aquele em que houve menor necessidade de parada do sistema para o desentupimento e limpeza do sistema de membrana e, paralelamente, foram as condições na qual foi observado o maior fator de concentração do soro (fator de ordem 6).

\section{AGRADECIMENTOS}

Os autores agradecem ao laticínio envolvido nesses estudos pelo fornecimento das amostras bem como dos laboratórios para o desenvolvimento desse estudo.

\section{REFERÊNCIAS}

AKOUM, O.; JAFFRIN, M. Y.; DING, L. H.; FRAPPART, M. Treatment of dairy process waters using a vibration filtration system and NF an RO membranes. Journal of Membrane Science, v. 235, p. 111 - 122, 2004. http://dx.doi.org /10.1016/ j.memsci.2004.01.026

AMERICAN PUBLICA HEALTH ASSOCIATION - APHA; AMERICAN WATER WORKS ASSOCIATION - AWWA; WATER ENVIRONMENT FEDERATION WEF. Standard methods for the examination of dairy products. $17^{\text {th }} \mathrm{Ed}$. Washington DC., 2004. 552 p.

AYDINER, C.; TOPCU, S.; TORTOP, C.; KUVVET, F.; EKINCI, D.; DIZGE, N.; KESKINLER, B. A novel implementation of water recovery from whey: forwardreverse osmosis integrated membrane system. Desalination and Water Treatment, v. 51, n. 4-6, p. 786-799, 2013. http://dx.doi.org/10.1080/19443994.2012.693713

BALANNEC, B.; GUIZIOU, G. G.; CHAUFER, B.; BAUDRY, M. R.; DAUFIN, G. Treatment of dairy process water by membrane operations for water reuse and milk constituents concentration. Desalination, v. 147, p. 89-94, 2002. http://dx.doi.org/10.1016/S0011-9164(02)00581-7

BRASIL. Ministério da Agricultura, Pecuária e Abastecimento. Instrução Normativa $N^{\circ} 62$, de 29 de Dezembro de 2011. Diário Oficial [da] União, Brasília, 29 dez. 2011.

BRASIL. Ministério da Agricultura, Pecuária e Abastecimento, Brasil. Portaria № 53 Projeto de Instrução Normativa que estabelece os padrões de identidade e qualidade de soro de leite, de 10 de Abril de 2013. Diário Oficial [da] União, Brasília, 10 abr. 2013.

FlORÊNCIO, I. M.; FlORENTINO, E. R.; SILVA, F. L. H.; MARTINS, R. S.; CAVAlCANTI, M. T.; GOMES, J. P. Produção de etanol a partir de lactossoro industrial. Revista Brasileira de Engenharia Agrícola e Ambiental, v. 17, n. 10, p. 1088-1092, 2013 
FOX, P. F.; MCSWEENEY, P. L. H. Dairy chemistry and biochemistry. 1. ed. London: Thomson Science, 1998. 378 p.

GILLIES, M. T. Whey processing and utilization: economic and technical aspects. [S.1.]: Noyes Data Corporation, 1974.277p.

LOURES, C. C. A.; IZÁRIO FILHO, H. J.; SAMANAMUD, G. R. L.; SOUZA, A. L.; SALAZAR, R. F. S.; PEIXOTO, A. L. C. et al. Performance evaluation of photofenton and fenton processes for dairy effluent treatment. International Review of Chemical Engineering (IRECHE), v. 5, n. 4, p. 280-288, 2013.

MILLER, G. D.; JARVIS J. K.; MCBEAN L. D. Handbook of dairy products and nutrition. $2^{\text {nd }}$ Ed. Illinois: CRC Press, 2000.

MIZUBUTI, I. Y. Soro de leite: composição, processamento e utilização na alimentação. Semina: Ciências Agrárias, v. 15, n. 1, p. 80-94, 1994. http://dx.doi.org/10.5433/16790359.1994v15n1p80

MOREIRA, R. W. M.; MADRONA, G. S.; BRANCO, I. G.; BERGAMASCO, R.; PEREIRA, N. C. Avaliação sensorial e reológica de uma bebida achocolatada elaborada a partir de extrato hidrossolúvel de soja e soro de queijo. Acta Scientarum Technology, v. 32, n. 4, p. 435-438, 2010. http://dx.doi.org/10. 4025/actascitechnol .$v 32 \mathrm{i} 4.5739$

MORR, C. V.; HA, E. W. Whey protein concentrates and isolates processing and functional properties. Critical Reviews in Food Science and Nutrition, v. 33, n. 6, p. 431-476, 1993. http://dx.doi.org/10.1080/10408399309527643

OLIVEIRA, D. F.; BRAVO, C. E. C.; TONIAL, I. B. Soro de leite: um subproduto valioso. Revista do Instituto de Laticínios Cândido Tostes, v. 67, n. 385, p. 64-71, mar./abr. 2012. http://dx.doi.org/10.5935/2238-6416.20120025

ORDOÑEZ, J. A. Tecnologia de alimentos: componentes dos alimentos e processos. Tradução Fátima Murad. Porto Alegre: Artimed, 2005. Vol. 1. 294 p.

REVILLION, J. P.; BRANDELLI, A.; AYUB, M. A. Z. Produção de extratos de leveduras de uso alimentar a partir do soro de queijo: abordagem de elementos técnicos e mercadológicos relevantes. Ciência e Tecnologia de Alimentos, v. 20, n. 2, p. 246-247, 2000. http://hdl.handle.net/10183/19328

SALAZAR, R. F. S.; OLIVEIRA, M. F.; ALCÂNTARA, M. A. K.; IZÁRIO FILHO, H. J. Evaluation of a system for dairy wastewater treatment composed by photochemical $\left(\mathrm{TiO}_{2}\right.$ fixed / $\mathrm{UV}_{\text {solar }}$ ) and biological (aeration pond) reactors. International Review of Chemical Engineering (IRECHE), v. 5, n. 4, p. 294-300, 2013.

SOUZA, R. R.; BERGAMASCO, R.; COSTA, S. C.; FENG, X.; FARIA, S. H. B.; GIMMENES, M. L. Recovery and purification of lactose from whey. Chemical Engineering and Processing: Process Intensification, v. 49, n. 11, p. 1137-1143, 2010. http://dx.doi.org/10.1016/j.cep.2010.08.015

SKUDDER, P. J.; GLOVER, F. A.; GREEN, M. L. An examination of the factors affecting the reverse osmosis of milk with special reference to deposit formation. Journal of Dairy Research, v. 44, p. 293, 1977. 
SPANGLER, P. L.; AMUNDSON, C. H. Concentration of milk and whey using composite, spiral wound, reverse osmosis membranes. Journal of Dairy Science, v. 69, n. 6, p. 1498-1509, 1986. http://dx.doi.org/10.3168/jds.S0022-0302(86)80565-3

TAWFIK, A.; SOBHEY, M.; BADAWY, M. Treatment of a combined dairy and domestic wastewater in an up - flow anaerobic sludge blanket (UASB) reactor followed by activated sludge (AS System). Desalination, v. 227, n. 1/3, p. 167 - 177, 2006. http://dx.doi.org/10.1016/j.desal.2007.06.023

TOLEDO, R. T. Improving fermentation productivity with reverse osmosis. Food Technology, v. 38, n. 12, p. 92-96, 1984.

VOURCH, M.; BALANNEC, B.; CHAUFER, B.; DORANGE, G. Treatment of dairy industry wastewater by reverse osmosis for water reuse. Desalination, v. 219, p. $190-$ 202, 2008. http://dx.doi.org/10.1016/j.desal.2007.05.013

ZENEBON, O.; PASCUET, N. S.; TIGLEA, P. Métodos físico-químicos para análise de alimentos. São Paulo: Instituto Adolfo Lutz, 2008. 